\title{
See You Tomorrow: A case study of the Understanding Cinema project at Granton Primary School in Edinburgh
}

\author{
Aoife Donnelly and Avril Whelan - Granton Primary School, Edinburgh, UK \\ Jamie Chambers* - University of Edinburgh, UK
}

\begin{abstract}
This case study describes the experience of 'Le cinéma, cent ans de jeunesse' and the Understanding Cinema project at an after-school film club at Granton Primary School in Edinburgh from 2016 to 2017. It does so from the perspective of the teachers, filmmaker and students involved and focuses in particular on the production of the students' film See You Tomorrow, about a young girl dealing with racist bullies. Exploring the processes undertaken as part of the project and the students' responses to them, this study ultimately advocates for the benefits of using both practical and theoretical approaches to film in primary classrooms.
\end{abstract}

Keywords: film in the classroom; film club; Bergala; film literacy; cultural agency; racism

\section{Introduction}

Made as part of the Centre for the Moving Image's Understanding Cinema project (the Scottish incarnation of the Cinémathèque française's 'Cinéma, cent ans de jeunesse' project), See You Tomorrow is a short film made by a group of five Primary 6 (P6) (ages 9-10) and Primary 7 (P7) (ages 10-11) children from Granton Primary School in Edinburgh. Here we offer a short case study of both the film and the project in which it was made, from the perspective of the two classroom teachers (Aoife Donnelly and Avril Whelan) who ran the project, the film-maker assigned to work with the group (Jamie Chambers) and some of the key students involved in making the film (Khadija, Maggie and Arwyn). In doing so, we endeavour to place the film within the wider context of using film in primary classrooms in Scotland.

We have chosen to write largely using collective pronouns ('we', 'us') or in the third person identifying each of our participants by name, but in places we have made space for one of us, or one of our project participants, to speak in the first person, in the form of a quotation.

The film ECOSSE - See You Tomorrow can be watched on the Vimeo website: https://vimeo.com/221750662 (accessed 22 February 2018). 


\section{Granton Primary School and previous experiences of cinema}

Granton Primary is a growing school with a roll of almost five hundred children. At least 77 per cent of our learners live in SIMD (Scottish Index of Multiple Deprivation) areas with a rating of 1 or 2, and are thus from recognized areas of considerable disadvantage. A significant number of our students also have additional support needs. Many students are on the child protection register and Granton also has a transient sector of learners due to the temporary/emergency housing in our catchment specifically for vulnerable families. Speaking in 2010, education scholar Martyn Rouse discussed the vast gap between high achievers and low achievers in Scotland. Rouse suggests that the gap emerged primarily as a result of hereditary familial poverty, from a state of disadvantage passed down through generations. In an attempt to address this situation, the Scottish government has implemented various policies over the past decade, such as the Early Years Framework (EYF), Curriculum for Excellence (CfE) and the Child at the Centre and Getting it Right for Every Child (GIRFEC), in an attempt to break the negative cycle perpetuated by social class, and to bridge the gap between privileged and disadvantaged. In setting up a film club at Granton Primary School to run the Understanding Cinema Project, we took care not to discriminate between privileged or disadvantaged, or high and low achievers, or between native-speakers of English and children whose first language was not English. We felt strongly that we wanted to offer every child the opportunity to feel a sense of achievement after each session.

Prior to their involvement with Edinburgh Filmhouse and the Understanding Cinema programme, neither Aoife nor Avril had had much experience of working with film. Both enjoyed watching films yet had never considered how they were made. As Aoife describes:

The extent of our insights focused on acting and perhaps sound, but framing and shot-types would never have registered with us due to a complete lack of awareness of film-making. However, our inherent desire to keep learning and seek out new experiences for ourselves as professionals and for our pupils essentially drove us to become involved.

In 2015, Aoife was teaching a P7 (ages 10-11) class when a colleague informed her about Understanding Cinema, a programme her colleague had previously participated in while working at another school in East Lothian. He spoke highly of the individuals involved in Understanding Cinema and outlined to Aoife, with considerable enthusiasm, what he saw as the significant benefits that his pupils had gained from their involvement in this project (such as one student whose sense of confidence and wider cultural agency was boosted by the project to the extent that his spelling age increased by several years over a period of months). Convinced, Aoife put herself forward to participate in Understanding Cinema 2015/16. Aoife describes feeling intimidated before attending the initial training:

When I attended the Understanding Cinema training at Edinburgh Filmhouse, I was utterly terrified as I had absolutely no idea about what this would entail or what would be expected of me. The day was spent in the company of film-makers, teachers and professionals involved with Edinburgh Filmhouse. In addition to a short filming session, we were informed of the origins of the project, viewed the assigned footage and were provided with a detailed outline of the course curriculum. 
Taking its programme of activity from 'Cinéma, cent ans de jeunesse' (CCAJ), Understanding Cinema revolves around an annual topic, which in 2015/16 was 'weather'. Aoife's P7 class was assigned a film-maker, Jamie Chambers, who began working with the class on a fortnightly basis. Aoife and Jamie formulated a schedule whereby Jamie would provide input every two weeks, using film clips to support his teaching, and Aoife would follow up with a practical film-making session the following week. Aoife found that this schedule fitted neatly into the already busy P7 timetable, and feels that this way of working with Understanding Cinema has probably been her most functional experience of the project to date.

During the sessions with Jamie, pupils were given the opportunity to discuss shots and framing, as well as more in-depth matters, such as how to portray a feeling without verbalizing it and how to elicit the emotions of the viewer through film. As part of teaching the group the importance of showing emotion visually rather than using words to tell an audience what to feel, Jamie asked the group to take a series of photographs. He emphasized the importance of camera placement and, in particular, of thinking about the actor's facial expression and body language to highlight their emotions to the audience. This task got the groups thinking about how to frame each shot in order to convey the actor's emotions. The pupils then applied this knowledge during acting and filming, and Aoife soon began to notice clear developments in their thought processes before hitting the record button. Participants were provided with clear expectations of what was required of them for each activity, as well as visual and attainable guidelines on what they could potentially achieve. As the year progressed, pupils increasingly used their own film footage to reflect and evaluate, rather than using external clips. Through in-depth and candid discussion, participants shared their opinions and learned from their experiences, taking advantage of the wisdom gained from making mistakes. For example, while reviewing footage, it might become apparent to a group that their camera was slightly askew during shooting. While this may not have been too noticeable when filming, it would be significantly more obvious when watching on a large screen. The group would realize that, although a potentially good scene, the footage could perhaps not be used if the camera did not provide a sufficiently stable viewpoint. Through this discussion and reflection, the group would then learn to ensure their camera was straight and stable before beginning filming again. Allowing the pupils to make mistakes and see these errors for themselves was far more valuable than providing them with a list of instructions in advance. By evaluating footage, the pupils were able to come to their own decisions as to what worked and what did not work, and they were then able to use these self-imposed restrictions and guidelines to inform their own progress. Each session was concluded with specific instructions to shoot a film clip meeting several criteria. Initially, these criteria focused on using a static camera, considering framing and the use of a variety of angles. Later, this progressed to encompass more ambitious and advanced modes of film-making, and ultimately a final short film. Over the course of the academic year, Aoife went on to acquire an understanding of, and competence with, film-making alongside the children, offering support and guidance when she felt able:

As a technophobe, I was wary of operating the cameras and editing software, and I was concerned about my ability to do so appropriately. However, the pupils were more than capable and I found myself grasping the use of this alien equipment with relative ease. The depth with which I was enabled to delve into Understanding Cinema with my class that year 
established a skill set and a confidence in myself to further engage with projects aimed at teaching the film-making process.

\section{Working with film in the classroom}

In our experience, one primary challenge of teaching film in the classroom is a general lack of confidence among teaching professionals. As teachers who had never before received any formal training and had no prior experience of the practice of filmmaking, we would not have considered attempting to teach such a topic, given our lack of relevant skills, and we believe many other teachers would feel the same. The considerable benefit of a programme such as Understanding Cinema therefore is that, through the involvement of film-makers in the classroom, it teaches not only pupils but also teachers how to create films through ways of working that can subsequently be recycled year after year (without the presence of the film-maker), thus providing teachers with just enough expertise to remain one step ahead of their pupils. The structure of such a programme ensures that teachers' own learning, and that of their students, is scaffolded through a series of exercises aimed at gradually developing the basic skills of film-making.

In primary school, time is a constant issue. In Scotland, where we are often told that literacy and numeracy attainment levels are not reaching their potential, these curricular areas are an absolute priority for schools. Furthermore, as Granton is an area of intense social deprivation, more and more children are joining Primary 1 without significant exposure to, and engagement with, spoken and written language. As a result, the teaching of language and number tends to take up the majority of the school week. Granton has also committed to teach two hours of quality physical education each week, and thus little time remains to meet surplus curricular outcomes, such as social studies, science, technology and the expressive arts. Undertaking a project such as Understanding Cinema can therefore be a considerable strain on precious time.

The Scottish Curriculum for Excellence, however, was established specifically to facilitate a sense of flexibility and allow a degree of creative input on the part of teachers previously hindered by its somewhat more didactic predecessor, the 5-14 Curriculum. In our experience, the 5-14 Curriculum left little scope for teachers to adapt the learning to suit each learner's needs. Curriculum for Excellence, designed for ages 3 to 18, not only seeks to instil students with a rigorous academic education but also looks to prepare them for life beyond school by developing their capacities as responsible citizens, confident individuals, successful learners and effective contributors. (All of these capacities, we would argue, are met by the Understanding Cinema programme.) By spreading outcomes over two or three years, Curriculum for Excellence is also considerably less restrictive than 5-14 about when specific outcomes had to be covered, meaning there is more scope to postpone coverage of learning experiences to allow for extra-curricular projects to take place.

Since Granton is an area of significant social deprivation, many of our pupils may have narrower life experiences than their peers in more affluent areas. One of our principle aims as a school has thus been to ensure that our students gain life experience, and that we assist in developing their non-academic strengths, particularly for those who struggle with literacy and numeracy. In our experience, programmes such as Understanding Cinema allow significant scope for this to take place. In the two years Aoife has been involved with the programme, she has observed less able pupils excel in this area of learning, which has helped to boost their self-esteem and, in turn, their academic work due to a new-found confidence and interest in learning in general. 


\section{Understanding Cinema 2016/17: Play}

In 2016/17, Aoife approached her colleague Avril in order to help her run Understanding Cinema as a film club, which met weekly on Tuesdays after school for just over an hour. Once again, Granton was assigned a film-maker, Jamie Chambers, who joined the film club every Tuesday.

The group consisted of a combination of approximately twenty Primary 6 and 7 pupils (ages 9 to 12 years) who had chosen to sign up to a programme of extracurricular activity. The annual topic, inherited from 'Cinéma, cent ans de jeunesse' was le jeu or play. A series of exercises helped children explore cinematic representations and embodiments of play (see Figures 1 and 2), before moving towards final short films that foregrounded a scene of play.
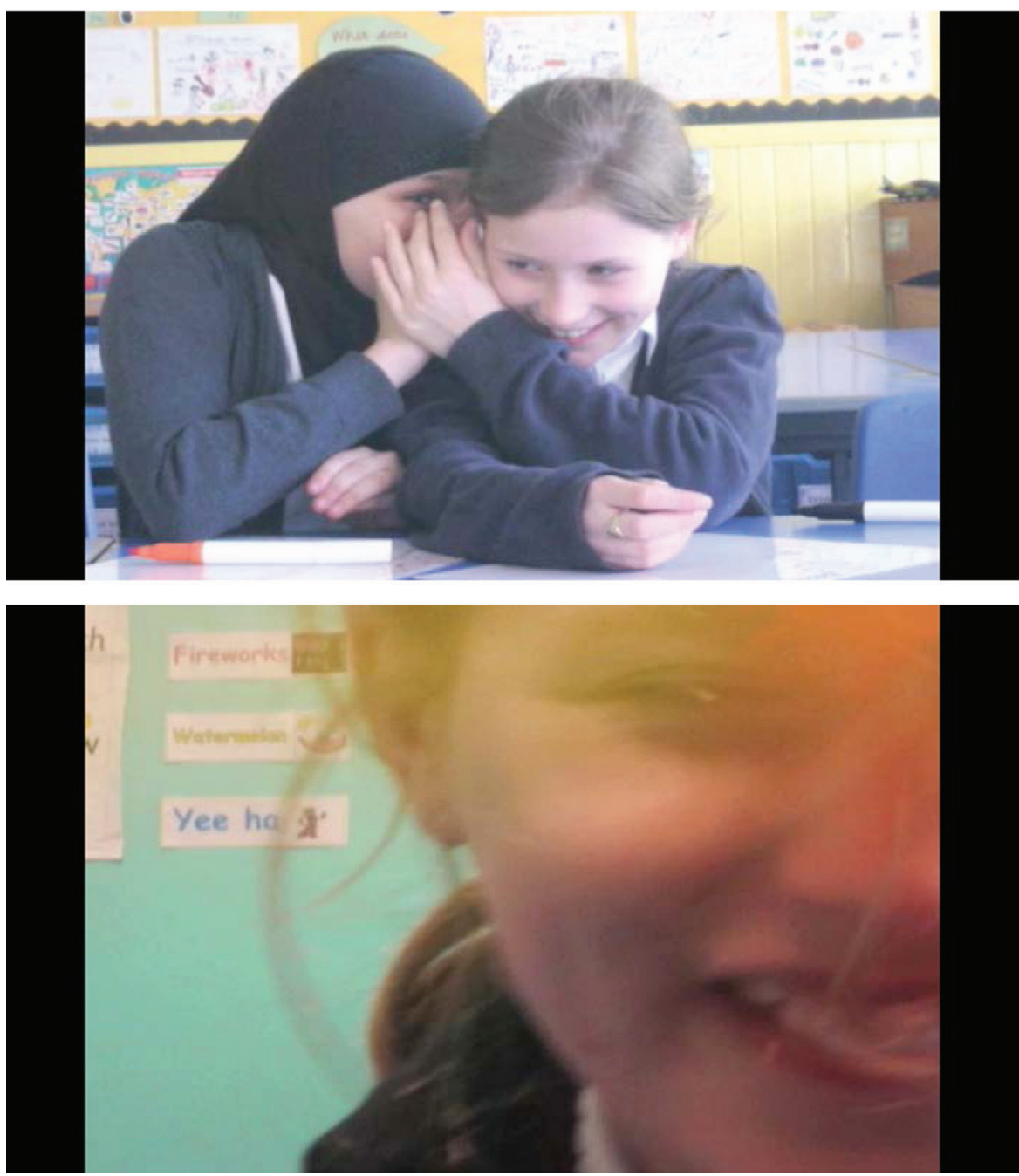

Figure 1-2: Some of the film club's early exercises exploring the theme of play

Core session time with Jamie was allocated to teaching input, watching footage and indepth discussions. Jamie's sessions with the pupils revolved around showing the pupils each other's work and deconstructing and commenting on what we liked and disliked about each shot. If something seemed not to work, Jamie saw it as an opportunity to discuss how to make it better by getting suggestions from other members of the film club or by offering his own suggestions. The discussion following the viewing of each 
clip was perhaps one of the crucial moments in which pupils learned to evaluate and reconsider their own approaches to film, both as film-makers and as audience members.

Early on in the year, the club was split into four film-making groups of four or five pupils each. Practical film-making tasks initially took place outside the core film club session, at playtimes and lunchtimes. As the year progressed, however, a short 40-minute slot was utilized during school assembly in order to release Aoife and Avril to complete filming assignments with each of the groups. Consequently, time to film was very restricted and this was undoubtedly the greatest challenge we encountered when approaching Understanding Cinema as an after-school film club. Aoife feels that a significant advantage of running Understanding Cinema with her own class within class time (as she had done the previous year) was the ability to be more flexible with timetabling, and thus to have the ability to choose the most appropriate times to complete filming exercises, rather than being confined to fixed times.

There were, however, also many benefits of choosing an extra-curricular, afterschool approach to Understanding Cinema, specifically regarding the pupils' attitudes towards, and willingness to engage with, the programme. As a result of the opt-in policy, the film club largely consisted of individuals who already possessed an interest in film, were willing to give their time and genuinely wanted to participate in the programme. This immediately dispelled some of the challenges Aoife had experienced the previous year when running the project during class time, when some pupils lacked interest and, therefore, did not always take the filming exercises seriously. The relative motivation of the film club pupils also meant that, when the participants were required to film during their break and/or lunchtime, they were perhaps more willing to do so than pupils who had not been given an option about their involvement.

The pupils in the film club gelled well almost instantly. Friendship groups were immediately apparent as the majority of the pupils were in P6 and already knew one another well. Those few from P7 mingled happily with the P6 cohort, enabling a sense of openness within the group as a whole. Looking back on the project, something that struck us as remarkable was the pupils' ability to offer and receive feedback and criticism in a constructive and mature way. This was, in part, due to the dynamic of the group itself but also something that was gradually fostered over time through regular sessions in which footage would be evaluated. At the beginning of the programme, the pupils were reluctant to criticise the work of other groups, especially those that included their friends. However, teaching pupils to offer and accept criticism was afforded equal importance as the teaching of film-making skills. Jamie achieved this by modelling how to give feedback that was sensitive and constructive, and the pupils quickly adopted this approach. For example, while viewing footage during one session, one of our pupils commented he could not see the faces of the actors clearly enough to understand the emotions of the scene as he felt the camera was placed too far away from the actors. He suggested that the group should place the camera closer to the actors for scenes with important dramatic moments and dialogue. By beginning each weekly session with an opportunity to assess and review previous footage, the pupils slowly built up the ability and confidence to offer their personal opinions without worrying about causing offence. This provided the cameraperson or director with a chance to explain (or defend) why they made certain decisions, such as about camera placement or type of shot, which, in turn, further embedded the importance of consciously considering these things before and during filming. This also helped to foster principles of social cooperation within the groups, which we believe is a considerable benefit of a programme such as Understanding Cinema. 
In our experience, Understanding Cinema allowed pupils to express themselves in a number of ways, through their roles in the film-making process. As scriptwriters, participants drew on genuine life experiences to share and express in their films. In doing so, pupils made themselves vulnerable to both the viewer and their peers. Yet their drive to find sincerity and credibility in their stories propelled them onwards. Perhaps their films also provided them with an unanticipated outlet, for at such a delicate age, film can act as a medium for sharing things with an audience without exposing oneself entirely. Writers experienced the additional challenge of dealing with the opposing opinions of others - how to react when group members attempted to alter details of the story. This can be particularly difficult when stories are of a personal nature, and yet we found that the group responded to such challenges well.

As actors, pupils were offered an opportunity to shed their skins and adopt the role of someone else. Such occasions allowed them to disguise themselves and, to an extent, allowed them the opportunity of taking a break and withdrawing from their own lives. In certain instances, the roles they assumed were perhaps more exciting than the roles they felt allowed to play in their own lives; in other instances, the roles perhaps helped them to empathize with others. Some parts proved challenging for the pupils, yet in almost every instance they showed maturity in stepping up for the good of the film. Several stories contained bullying of some kind, including the use of homophobic and racial slurs, and actors initially expressed their reluctance to verbalize such insults, particularly on camera, but ultimately did so for the good of the film. In general, the films provided students at a vulnerable and formative age with a safe environment in which to explore grittier elements of society and human interaction.

Directors within the group were faced with the dilemma of finding a balance between being assertive and being outright bossy. Here, being confident is an advantage but being overconfident can lead to insurrection within the group. While working with Understanding Cinema with her P7 class in 2015/16, Aoife discovered that one of her most academically capable pupils found the process of trying to corral a group of his peers an enormous challenge. Although fairly confident in his own ability to work the camera, at times he struggled to move beyond his own gentle, more introverted sense of confidence when attempting to direct and manage the members of his team. As we found also with the film club in 2016/17, however, Understanding Cinema helped to foster and nurture these skills in a secure environment.

Indeed, reflecting now upon our work during 2016/17 it strikes us that, while the focus of Understanding Cinema is on strengthening children's engagement with, and understanding of, film (both as audience members and film-makers), there are a great many other parameters in which participating in film education projects of this sort can be beneficial. Principally, we were very struck as to the benefits of the programme in terms of emotional literacy and personal development. In our experience, a programme such as Understanding Cinema offers students a valuable chance to express themselves, to reflect upon and work through some of the more complicated issues in their lives within a relatively safe environment, and to gain a greater sense of confidence and social agency. 


\section{Final film: See You Tomorrow}

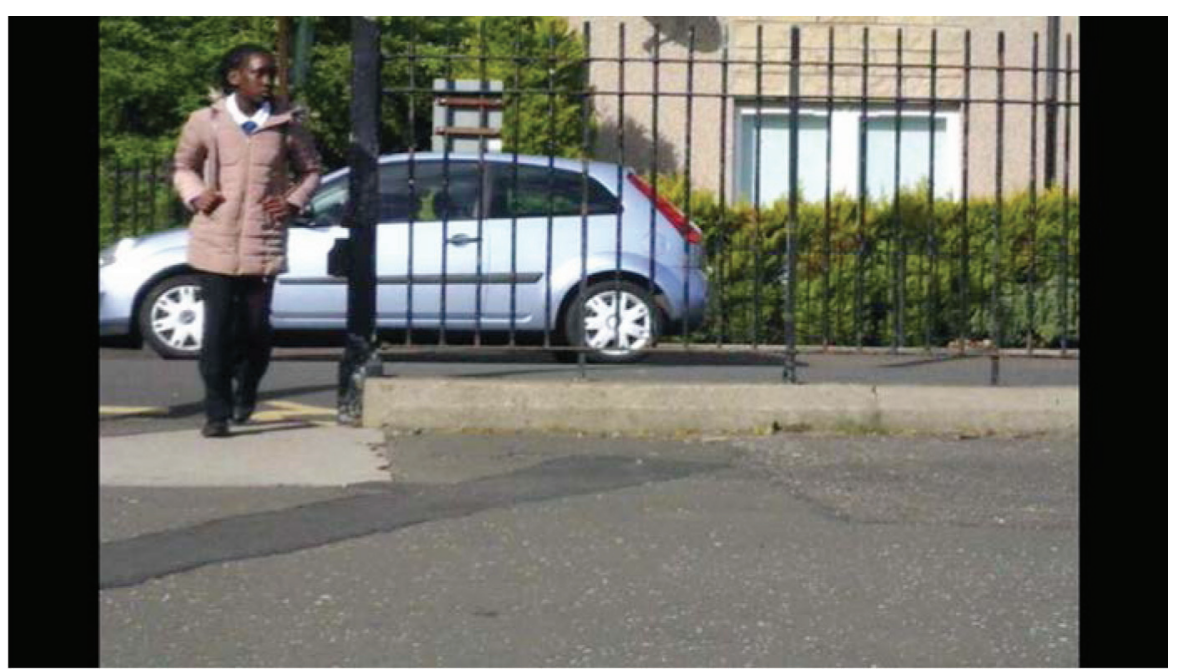

Figure 3: Khadija arrives at school in See You Tomorrow

After a series of shorter, more exploratory, exercises, students were tasked by CCAJ's 'Rules of the Game' to make a short film 'where the story is interrupted at a certain moment, when a character finds their freedom through playing, which allows them to escape from the confines of their everyday reality'.

See You Tomorrow was the response to this brief from the group comprising Maggie (camera, director), Khadija (the film's star; see Figure 3), Arwyn (the film's antagonist, and a key contributor to script development) and co-stars Aiesha and Ollie. The script arose almost entirely from the children's own ideas, and particularly the group's idea that a story of bullying might resolve itself through a climactic dance-off. All the groups were initially challenged by Jamie to think of a problem that occurred for a character either in school or at home, and a way this problem might somehow be negotiated or overcome through play. Avril describes how:

as an adult, thinking about play I had many perhaps contrived ideas of what play was. However, the beauty of a project like Understanding Cinema is that it is led by the children themselves and their own creative, instinctive sense of play.

Maggie, Khadija, Arwyn, Aiesha and Oliver discussed and thought through a series of different ideas before agreeing to focus on a story that, to an extent, dealt with racism, which they all agreed was a problem not only in schools but more widely in society. Khadija, Aiesha and Maggie have aspects of African and Asian heritage respectively, and the group handled the discussions surrounding these issues in the script sensitively and with maturity. The group explicitly sought consent from Khadija, playing the character experiencing racist abuse, about whether she was happy for such elements to be included in the story, and to experience them as an actor in the film. The discussions of racism within the group illustrated the remarkable degree to which children between 9 and 12 perceive and comprehend the adult world. The group discussed different levels of racism, from more overt forms to the subtler, but no less unacceptable, forms of microaggressions. Reflecting on the film six months after it was completed, Khadija says she feels it is important to make films about racism 'because 
it happens a lot in the world, and things like that'. (See Figures 4-7: Arwyn, Aiesha and Ollie bully Khadija before class.)

Avril and Aoife were particularly struck by the personal development of Maggie, cameraperson for See You Tomorrow, throughout her involvement with Understanding Cinema. Previously a quiet and reserved student, Maggie took on the role not only of recording the entire film but also of directing the group. Avril found the manner in which Maggie commanded the group's attention with her very systematic approach to shooting sequences extremely impressive to watch. Arwyn, a more exuberant, extroverted character, took direction when needed from Maggie.
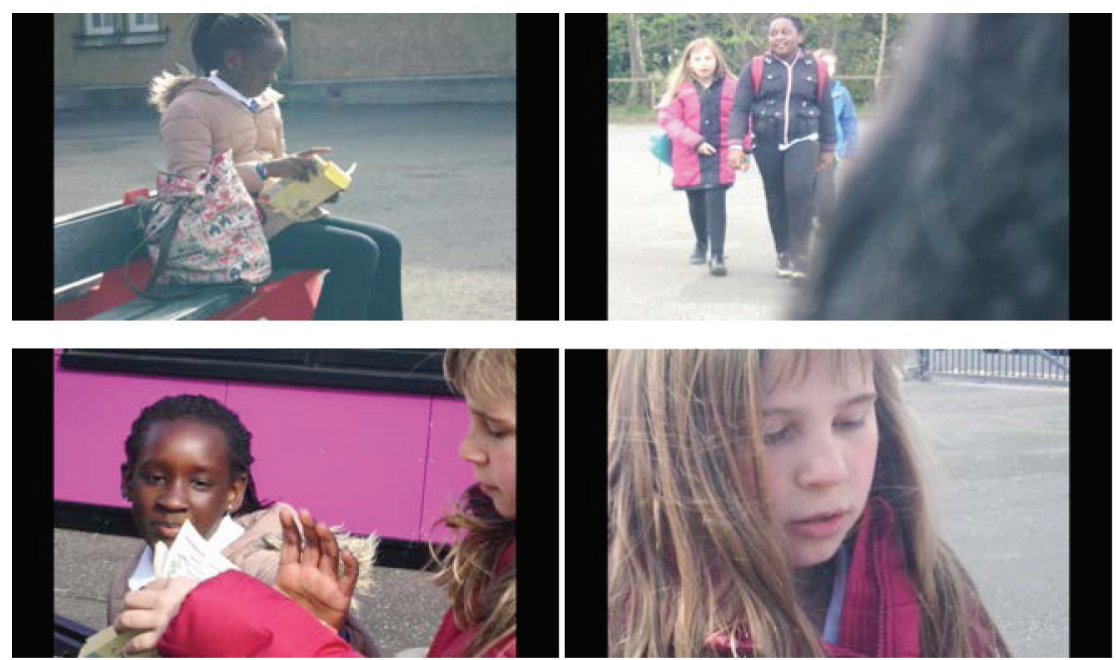

Figures 4-7: Arwyn, Aiesha and Ollie bully Khadija before class

The film was shot over a series of weeks on a small, mobile-phone-sized FlipVid camera (with in-camera sound), and was shot mostly independently by the group. Scheduling proved an ongoing challenge, particularly with film shoots for four separate groups to schedule. As the core film club meetings were all out of school hours, it was not possible to film during the film club's core session time as the group wanted to give the impression of a busy school and playground, and this could not be achieved with only the twenty participants in the film club. As mentioned above, Aoife and Avril managed to organize some extra time during the day on Fridays, finding roughly forty minutes to film each week while the rest of the school were at assembly. This proved feasible for small group scenes, such as the scene where notes are passed between Arwyn and Khadija in the classroom. However, many of the shots in the film required filming when other children were around. The group were therefore required to give up a lot of their own time to film during playtime and lunchtime, but they did so willingly and largely without complaint, which was reflective of the overall level of commitment among members of the film club. At one point, Maggie and Khadija even took home a camera on a Friday afternoon so they could film a scene at Khadija's house (a scene that sadly was later cut when the final film exceeded the length permitted by CCAJ).

A particular scene in the film that stands out for Avril is one in which Khadija is on detention alone in a room and hears music coming from an adjacent part of the school (see Figure 8):

The scene was a sort of a happy accident as when the group were filming this, the P1 class were in the room underneath practising a music and dance routine and I just love how the group acted upon this and made it 
an integral part of their film. It shows us Khadija's character coming alive and expressing herself through dance.

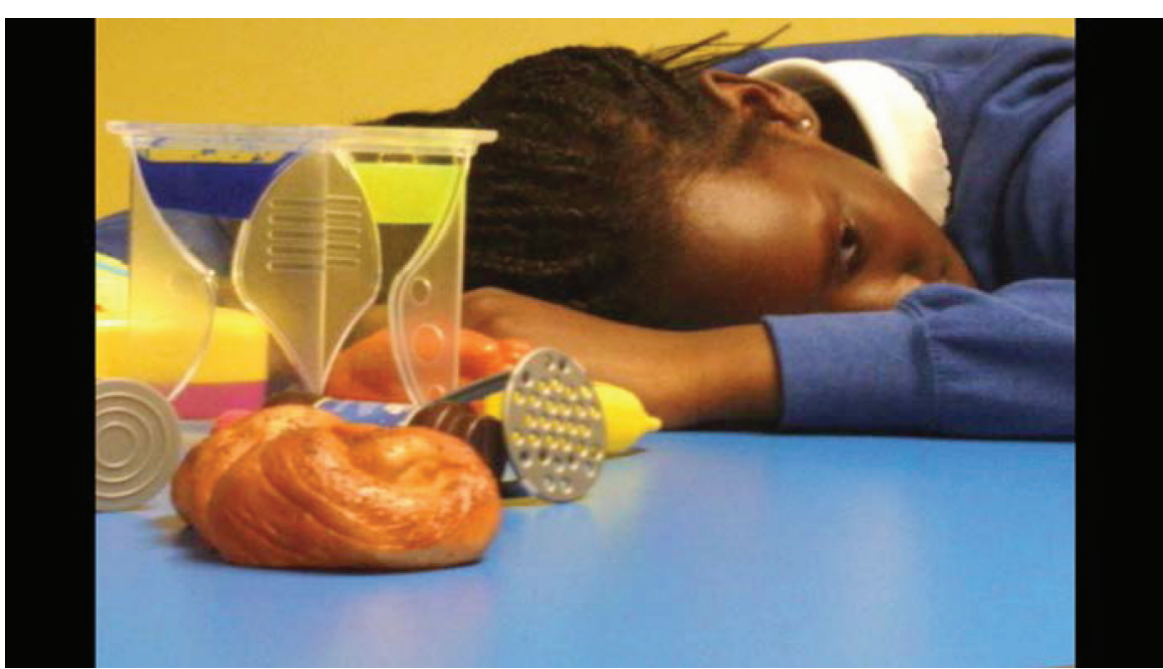

Figure 8: Khadija kills time in the detention room

Towards the end of the process, Jamie spent two full days shooting with the group in order to help them capture some of the more challenging scenes, such as the climactic dance-off, which was recorded over several days. Much of the film's material, however, remains footage that the group shot without the presence of a film-maker, such as the scene in which Arwyn passes nasty messages to Khadija (see Figure 9), and another accomplished classroom scene (which also, sadly, had to be cut due to the film's running time) in which Khadija seems anxious about leaving school.

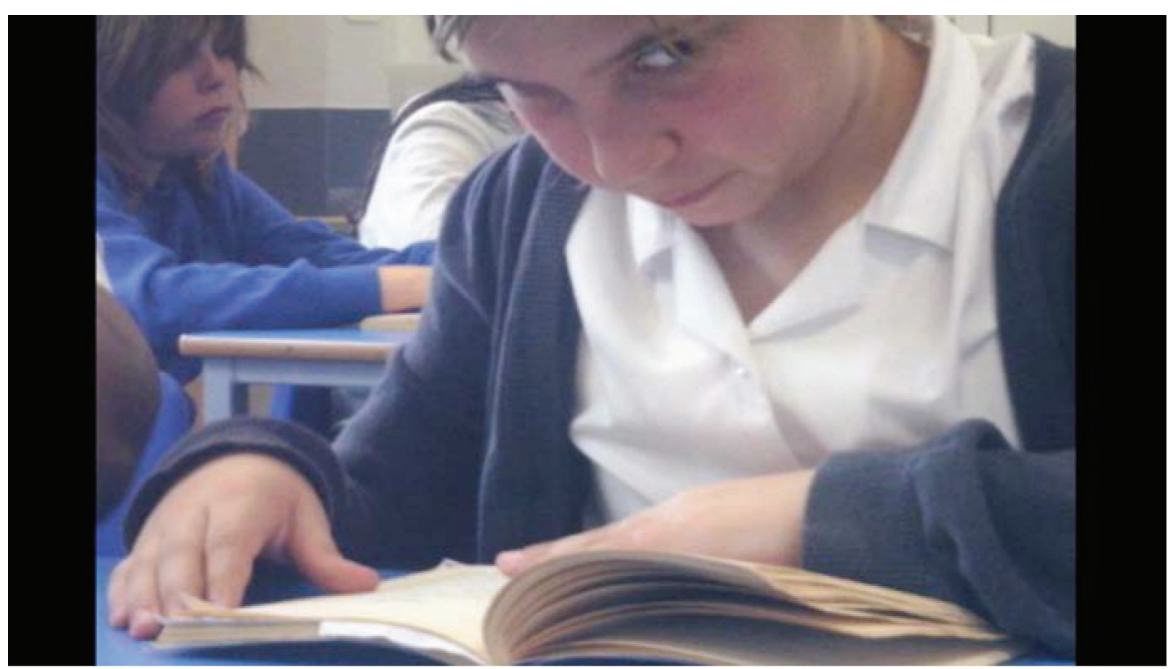

Figure 9: Arwyn hatches a cruel plan

With time running extremely short, Jamie edited the film using notes from the group, unlike the previous year, in which Aoife's class performed their own edits. The finished film had a considerable impact on the class when it was first screened during a film club session, a few days from the final submission deadline. Avril describes how: 
I will never forget watching See You Tomorrow for the first time. While some of the scenes may have been shot in my presence, a lot of them weren't. Seeing what seemed to me a bunch of sporadic, random clips all fit together as a film with a hugely powerful message was very moving. Furthermore, the kids who wrote, directed, acted and filmed each and every scene (lots of times!) were speechless watching their hard work back. Seeing it all put together and to see their project turned into a film was something they were very proud of. I remember them saying 'that's so good, I can't believe we made that'. When the children told me about their ideas of solving Khadija's experiences of racism through a danceoff, I couldn't quite picture how it would work. Jamie, on the other hand, always had great faith that this would be successful, and how right he was! I particularly loved how little was said in this final scene. I will always remember the goosebumps I felt during the final scene when Khadija extended her hand to help Arwyn, both literally and metaphorically, after she had fallen (see Figures 10-13).
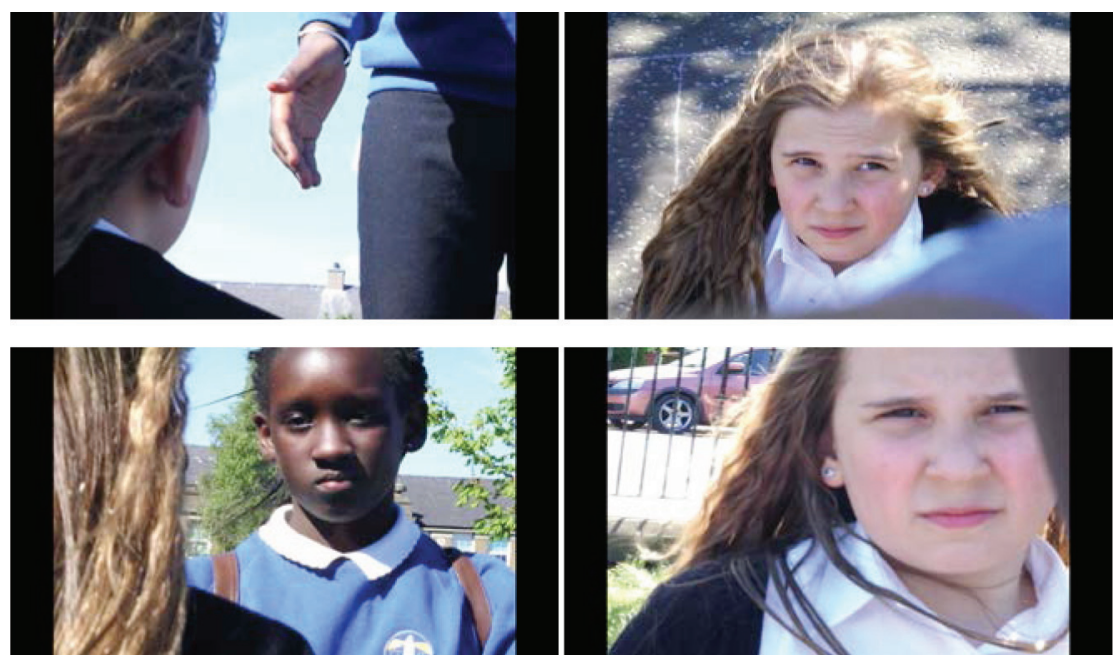

Figures 10-13: Khadija refuses to stoop to Arwyn's level

The film went on to receive a rapturous response when it was screened at the final CCAJ event in Paris, to a packed cinema audience of around eight hundred children from France, Finland, Lithuania, Portugal, England and Brazil. The audience did not even wait for the film to finish before they began applauding, clapping first during the sequence when Khadija wins the dance-off, then again at the sequence where she offers her hand to Arwyn to lift her up, and then finally along with the film's soundtrack as Khadija walks quietly yet triumphantly out of the school and the credits roll.

Demonstrating once again a considerable level of maturity, Maggie remarked to me that she felt part of the response the film received in Paris was down to the fact that many of the children in the audience came from parts of the world where racism was a much more focal, acknowledged issue than it is in Scotland. Avril describes how:

The children's faces when watching their movie on the big screen at the Cinémathèque and getting such a huge reaction is something I will always remember. The feeling of pride watching these children who got this 
opportunity not because of where they come from, but in spite of where they come from, was simply incredible.

The discussion session afterwards was similarly enthusiastic, and another round of applause broke out for Maggie, whose instinctual cinematography was singled out by CCAJ's artistic lead, the French film education theorist Alain Bergala, who described how he had been waiting for some time to see a film like See You Tomorrow, which so organically reconciled the instinctual, explorative, 'authentic' perspectives of children with the expressive parameters of cinema.

The journey to Paris itself was a new experience for the Granton film club, some of whom had never been on a plane before. The day after their screening at the Cinémathèque, the children had the chance to go sightseeing, which proved a significant event in the school year for many participants. Back in Scotland, See You Tomorrow was screened during a special assembly at Granton Primary School attended by the families of all the film club participants, where Khadija (who sadly was unable to join the trip to Paris) and her family were able to see it for the first time. More recently, the film has been screened in Brazil, by popular request from some of the students who saw it during the initial CCAJ screenings, and this is taken as a further mark of the film's success by Khadija and Maggie. Khadija describes her experience of taking part in See You Tomorrow as:

good, because I guess it improved my confidence. I'm normally shy and I don't really like seeing myself on TV and all that, or people watching, but then I was brave enough. I was nervous because I thought that people would not like it, but people liked it, so ...

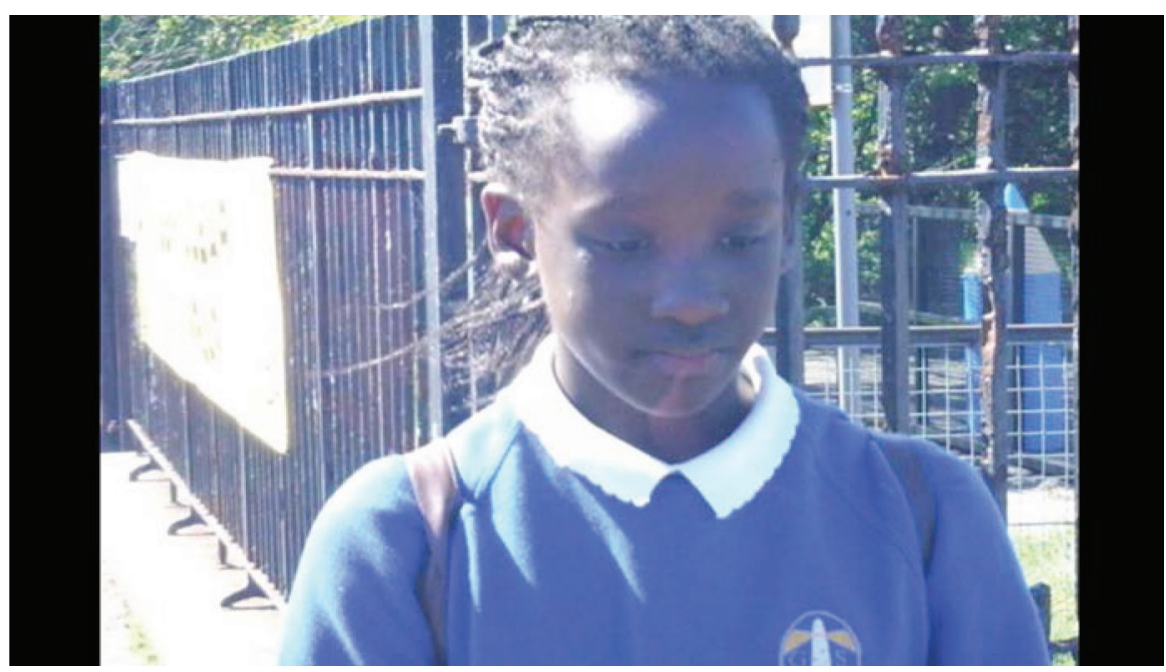

Figure 14: Khadija leaves school feeling happy in herself

Khadija and Maggie are now at high school, and meeting them half a year after their experiences with Understanding Cinema, Khadija already seems noticeably more confident and expansive than she was when the film club started. She seems aware of her considerable achievements with See You Tomorrow and says she would like to be involved in making more films. She describes how she has joined the film club at her new high school, where she is now trying her hand at directing and camera-operating. She is trying to persuade Maggie to join too, although Maggie - already somewhat 
beleaguered by the amount of work expected of her at the new school - seems like she will take some convincing.

\section{Conclusion}

Given their time working with the Understanding Cinema project, both Aoife and Avril are convinced about the merits of using film in the classroom. Before starting the film club, Avril felt Understanding Cinema would provide a good opportunity to develop skills that were in some way separate to the Scottish Curriculum for Excellence. She now describes her recognition that many of the skills she has learned through Understanding Cinema can be applied back in the classroom:

The creativity skills I developed I transferred into my everyday teaching. For example, becoming more aware of what makes a good story allowed me to give criteria to my class during a writing lesson. Furthermore, seeing how much a film clip can inspire the children in their discussions during film club, I used much more of these as a stimulus for literacy. If it benefited me as a teacher, I can only imagine the impact it had on the children who attended the film club.

Aoife ran an autonomous film class herself (without any input from Jamie) in Granton after her experience of Understanding Cinema in 2015/16, and similarly Avril began a mini film club group for six weeks with children from Primary 3-5 as an activity taking place during the children's 'golden time'. Both Aoife and Avril are continuing to work with Understanding Cinema during 2017/18 with increasing degrees of autonomy, and both feel strongly that there is a greater place for working with film as part of the curriculum.

Ultimately we feel that projects such as Understanding Cinema illustrate the considerable benefits of using film in the classroom, particularly through the manner in which they help children develop a sense of confidence and explore difficult social, personal and emotional issues through the relatively safe arena of cinema. Many of the students who worked on See You Tomorrow seem, from our perspective, to have significantly gained in self-confidence and a sense of self-efficacy as a result of their work on the film, and we believe that the film speaks for itself as an example of what children can accomplish under their own auspices within a supportive, creative educational environment.

\section{Notes on the contributors}

Aoife Donnelly is a primary school teacher at Granton Primary School, where she has been teaching since completing her PGDE at the University of Strathclyde in 2014. She has been working with Edinburgh Filmhouse and the Centre for the Moving Image on the Understanding Cinema programme for three years; she currently runs it as an after-school club with her colleague, Avril Whelan, and film-maker, Jamie Chambers.

Avril Whelan completed her PGDE at the University of Edinburgh and is a primary school teacher at Granton Primary School in Edinburgh. She started her teaching career there in 2014, and began working with Understanding Cinema two years later, with minimal filming experience. Avril currently runs an after-school film club with her colleague Aoife Donnelly and film-maker Jamie Chambers. 
Jamie Chambers is a postdoctoral fellow at the University of Edinburgh's Institute for Advanced Studies in the Humanities. He is the founding editor of the Film Education Journal and has worked as a film education practitioner with Understanding Cinema and 'Cinéma, cent ans de jeunnesse' since 2013. He is the curator of the Folk Film Gathering (the world's first folk film festival (www.folkfilmgathering.com)) and is the director of the award-winning, BAFTA-nominated films When the Song Dies (2012) and Blackbird (2013). 